there were chiefly in connexion with the navigation of the ship along the coast and piloting up the rivers when not stationed either at Pemba or Mombassa, both places having an evil reputation for the malarial nature of the climate. Whilst there he suffered from periodical attacks of severe neuralgia confined to the area described above, though much more severe, especially as regarded the photophobia and iritis. The attacks recurred regularly every fortnight, though occasionally three weeks would intervene, but this was rare. The attacks were always worst when he was stationed at Pemba. He stated that ague was not very prevalent in his ship, though three or four of the crew had been down with it. His attacks would last for twenty-four or forty-eight hours, rendering him totally unfit for duty, and to completely recover it always took one or two days more after the attack had ceased, as they left him so weak. Previonsly to joining the East Coast Squadron he had never been subject to any form of neuralgia. He was treated with antipyrin and other various nerve drugs, but derived no benefit. When the ship arrived at the headquarters of the squadron at Simon's Town he was informed that he was suffering from intractable neuralgia of the eye and was advised to come home to consult an ophthalmic surgeon on account of his eye. During the intervals of the neuralgia the patient was in no way troubled with his vision, the eye being quite equal to all tests applied, and no disease was to be made out by ophthalmoscopic examination. After leaving Simon's 'Town and joining the mail boat he was quite free from neuralgia until the morning of Dec. 23rd, when he consulted me. After thinking over his case and recollecting that malarial fever sometimes manifested itself in this manner, I treated him by giving him a large dose ( 15 grs.) of sulphate of quinine, with eight minims of liquor arsenicalis. This treatment gave him speedy relief, and he had no further trouble while on the ship.

My reasons for coming to the conclusion that this was a case of malarial fever are briefly stated as follows: (1) the periodicity of the attacks; (2) their regular recurrence; (3) the amount of prostration after the attack; and (4) that he was free from it when not stationed in a malarial district. The fact of his having had an attack after having left the malarial districts for three weeks goes in no way against the diagnosis, as it is a common occurrence for persons the subjects of ague to have an attack, even when they have been quite free from it for some considerable period, on becoming subject to a sudden change. This is especially the case where the change is from a warm climate into sudden cold, such as was experienced by the patient mentioned above, the difference in temperature between Dec. 20th and 22 nd having been for him a fall of $20^{\circ} \mathrm{F}$. Cold has often brought on attacks of ague in people travelling between South Africa and England unless averted by prophylactic treatment.

That malarial fever often exhibits itself in this form can easily be demonstrated in South Africa, where it is exceedingly common to find people suffering from orbital neuralgia who have been in the interior, where malaria is very prevalent, and who are only relieved by anti-malarial treatment. Their neuralgia is periodic and sometimes preceded by a definite cold stage. On looking over the literature of the subject I find that both my former teachers, Dr. Bristowe and Dr. Frederick Taylor of Guy's Hospital describe cases of so-called brow ague as belonging to the numerous anomalous manifestations of malarial fever. Their malarious nature may be recognised partly by their periodic character, by their occasional supervention on a more or less distinct cold stage, and by their occurrence in a malarious district, and partly by the fact that the patient has already been the subject of ague.

The scarcity of such cases in England has led me to think that the case above described might be of general interest and worthy of publication.

Camberwell-grove, S.E.

\section{DEATH UNDER NITROUS OXIDE GAS. ${ }^{1}$}

$$
\text { BY JOHN ADAMS, F.R.C.S. ENG. }
$$

THE account of the death under nitrous oxide gas, noticed in THE LANCET of March 3rd and gathered from newspaper reports, gives an imperfect description of the case. I was therefore pleased to accept an invitation from the secre-

1. A paper read before the Society of Anæesthetists on March 15th,
1891 . tary of the Society of Anæsthetists to give a more detailed account before its members who have made anæsthetics a special study, with the hope that some further light might be thrown on the unusual result, from what proves in the vast majority of cases a perfectly safo anæsthetic. The patient came to the dentist on Monday Feb. 21st, about 1.30 P.M., and had an hour previously partaken of a light lunch. After waiting half an hour, be was shown into the operating room on the first floor. $\mathrm{He}$ seemed in good health and wished to have a second right upper molar extracted whilst under gas. There was nothing tight about his neck, nor was there anything in his appearance to lead one to think he was not a fit subject for the anæsthetic. He had a small, receding jaw and a short, thick neck, but no abnormal swelling of any kind which prevented his closing his mouth, as reported in THE LANCET of the above date. An ordinary prop, attached to a strong fishing-line, was placed between the upper and lower central incisors. After taking three or four inspirations of nitrous oxide gas he took off the face-piece and said he felt nervous, but at his own request I proceeded to go on with the administration. His respiration was shallow but regular, and after taking about two thirds of the ordinary quantity of gas the tooth was extracted quickly and without any difficulty; the respirations at once became irregular and the patient became more cyanosed, his muscles rigid, and after three or four respirations he ceased to breathe, but no danger appeared imminent. Breathing not continuing, the prop was at once removed, the patient taken from the chair on to the floor, and artificial respiration commenced within thirty seconds after the extraction. The tongue was pulled forward. The heart was beating regularly but not strongly, the body remained rigid, and there was no inspiratory effort. About two minutes after the tooth was extracted, two or three expirations took place, showing there was no considerable obstruction in the larynx. Nitrate of amyl was applied to the nose and mouth; but as no inspirations took place it could not have affected the patient. A subcutaneous injection of ether was given over the præcordial region, as the action of the heart now became feeble. These measures failing, tracheotomy was performed within three minutes of the time the gas was discontinued to be administered; the position of the patient was awkward for the operation, and the extremely receding lower jaw, with a short, thick neck, made it somewhat difficult to perform, but as everything was at hand and ready assistance given I fortunately made an entrance through the upper rings of the trachea without loss of time. The tracheal wound was kept open, and on resuming artificial respiration a quantity of mucus (about an ounce) was forced out, nearly clear and only slightly bloodstained. Although one could hear air passing in and out of the opening in the trachea there was no voluntary effort of breathing from first to last. The patient now became still more cyanosed, and the heart could no longer be heard beating. Artificial respiration was continued for twenty minutes longer, although there was little hope of its being of use. Micturition took place after the commencement of taking the nitrous oxide, a symptom which I have not infrequently noticed when cyanosis becomes well marked, and. also in children. I will recapitulate shortly the methods adopted to restore respiration : (1) artificial respiration within half a minute after the patient ceased to breathe, (2) nitrite of amyl within one minute after respiration ceased, (3) subcutaneous injection of ether within two minutes after the patient had ceased to breathe, and (4) tracheotomy within three minutes after the patient had ceased to breatbe.

The necropsy was performed by Dr. Norman Moore, at the request of the coroner, twenty-five hours after death, in the presence of the medical attendant of the deceased and myself. Dr. Moore has kindly looked over and corrected the description of the morbid appearances The body was well nourished and muscular, of a man about twenty-six years of age. The face, neck, and back were all deeply cyanosed; there was a mark of a recent tracheotomy wound. Op removing the skull cap, which was unusually thick, venous engorgement was visible on the surface of the cerebral hemispheres; nothing abnormal was noticed in the cerebral substance. On opening the chest, the reins were noticed everywhere full of dark fluid blood. All the internal orgaris were healthy. The pericardium contained the normal amount of fluid. The heart was normal and the valves competent. All the cavities of the heart were empty, except a small quantity of fluid blood in the right ventricle. No clots were present. The lungs were engorged 
with dark fluid blood and were nearly airless. On opening the bronchi, the mucous membrane was dark in colour and engorged, and a quantity of thick mucus was found in all the larger bronchi. The trachea was also engorged, but contained less mucus. The upper three rings were divided. The larynx, tonsils, and tongue were removed together for examination. The larynx showed no swelling and very little engorgement, and contained no appreciable quantity of mucus ; no foreign body or abnormal substance was found. The tonsils showed old enlargement, but did not meet in the middle line. The stomach contained a small quantity of undigested food, with a good deal of ropy mucus. The œsophagus was normal. The liver, kidneys, and spleen were all dark in colour, showing venous engorgement, but without any signs of disease. The bladder was empty.

I have administered nitrous oxide gas to over 40,000 patients during the last twenty years and have never before had a fatal case.

In conclusion, it appears to me that the patient died from asphyxia, and the mucous membranes of the throat, larynx, and bronchi were perhaps peculiarly insensitive, for during the whole time of the administration of the gas, and subsequently, there was no symptom of irritation or coughing, as is often the case when a quantity of mucus gets into the air passages. The only point as regards treatment after the urgent symptoms showed themselves appears to me: Should tracheotomy have been done earlier? But then comes the question: How many times would tracheotomy have been performed unnecessarily? For in a large number of cases there are a certain few who, when embarrassment of breathing, with a considerable amount of cyanosis, takes place, soon recover, and to do tracheotomy without first resorting to other means would be incurring a slight risk from the operation itself, and it would leave a permanent mark of discredit on taking nitrous oxide. Now, as to the quality of the gas. Two cases were given from the same bottle immediately before, without the least unusual symptoms, and, thinking the question might be raised, I administered from the same bottle the next day with a good result, and have put it aside for any future investigation. The face piece which was used to administer the anæsthetic allows a small quantity of ordinary air to be inhaled through the outlet valve ; I cannot estimate the exact quantity, but I should think about 2 per cent. It is, in fact, the quantity which by experience has been found in the majority of cases to cause less cyanosis and stertor, without interfering with the prolongation of insensibility. I have endeavoured to state clearly the facts of this case ; it is distinct from those in which, during the administration of gas, a foreign body has fallen into the larynx and cause? death. I trust that neither experience nor the caution in administering anæsthetics to which experience ieads one were wanting, and I cannot offer any better explanatory uypothesis to the society than that well-worn one in other departments of medicine, "the idiosyncrasy of the patient." There were some special circumstances in his organism which made the temporary asphyxia from gas specially kiable to pass into a fatal form.

Aldersgate-street, E.C.

\section{d attitur}

$$
\text { OF }
$$

\section{HOSPITAL PRACTICE, BRITISH AND FOREIGN.}

Nulla autem est alia pro certo noscendi via, nisi quamplurimas et mor borum et dissectionum historias, tum aliorum tum proprias collectas habere, et inter se comparare.-MoRGaGNI De Sed. et Caus. Morb. lib. iv. Procmium.

\section{KING'S COLLEGE HOSPITAL.}

A CASE OF TUMOUR OF THE SPINAL CORD; REMOVAL OF TUMOUR ; DEATE.

(Under the care of Dr. FERRIER and Mr. W. WATson CheYNe).

WE give this week the account of a very interesting case of simple tumour growing within the dural sheath of the spinal cord and producing symptoms by increasing pressure on the cord. In this case the symptoms began with severe pain, and this was followed by motor paralysis, \&c. Through- out the illness pain was the most marked feature, rendering life almost unendurable. In the collection of recorded cases by Mr. Horsley the majority of intra-dural growths had pain as the first symptom, and the most numerous class was that of the myxomata or fibro-myxomata. Amongst the number of intra-dural growths (thirty-six) twenty-one were found in females and fourteen in males. At that period only two-one extra-dural and one intra-dural-had been subjected to operation; the latter had recovered completely, the former died. Since 1888 a few more patients have willingly accepted the chance of relief offered by operation. We have quite recently recorded a case ${ }^{1}$ in which operation, performed with gooa prospect of success, failed owing to accidental septic infection of the wound. The two cases may be compared with advantage ; they illustrate well the difficulties and risks of the operation and show the symptoms and physical signs which rendered accurate diagnosis of the seat of the lesion possible.

During his autumn holiday in the Shetland Islands, $\mathrm{Mr}$. Watson Cheyne was asked to see this patient by Dr. Taylor of Mid Yell. At this time both legs were completely paralysed, both as to motion and sensation, and there was incontinence of urine. The patient sat in bed with both legs drawn up, and the slightest movement induced violent and painful extension of the limbs, with agonising pain in the dorsal region. Mr. Cheyne was not able to examine the patient very carefully, but the history of the case and the symptoms presented led him to believe that he was suffering from a tumour pressing on the spinal cord. $\mathrm{He}$ accordingly advised that he should be sent up to London with a view to further careful examination, and, if it should appear advisable, operative treatment. He was accordingly admitted into King's College Hospital under the care of $\mathrm{Mr}$. Cheyne, by whom he was transferred to the care of Dr. Ferrier on his return from his holiday at the beginning of October.

Medical history of the case, by Dr. FwRRIER. - The patient, a man aged twenty-five, was admitted into King's College Hospital on Sept. 18th, 1892. He was a fisherman, living in Shetland. He had been married four years, and had one child. Until his present illness began he had always been in good health. He had never gse $\mathrm{n}$ intemperate, and had never had syphilis. His Father. who is alive and aged seventythree, is strong and healthy, as is also his mother, aged sixty-six. He as six brothers and five sisters. One brother died in infancy. About eiwht years ago he began to complain of paiu in the region of the lower ribs on the right side. The pain was worse when he stooped, and it was also wor:e at night, se that, it not infrequently disturbed his sleep. It was intermittent, and occasionally would cease entirely for a week or two. The pain shot backwards from the region above mentioned to the spine, and forwards towards the epigastrium. There was tenderness on pressure on this region. For the relief of the pain he sometimes received subcutaneous injections of morphia. Notwithstanding the pain, his general health and strength continued good, and he continued able to do his work until about two years ago. He then began to have some difficulty in lifting his right foot off the ground in walking, and be was obliged to keep his eyes on it, as otherwise he was apt to stumble. Along with the weakness of the right leg the sole of the right foot became "sore" or tender on standing. The left leg became similarly affected at a distinct interval after the right. $\mathrm{He}$ continued his employment for five months after the weakness showed itself in his legs. In June, 1891, he went into the Aberdeen Infirmary, where he was treated for a month. Shortly after leaving the Aberdeen Infirmary he had a very severe attack of pain in the right side and became unable to get about at all for a time. After three weeks he improved a little, the pain diminished, and in the following September he was able to get about with the aid of two sticks. In February of 1892 the pain became much more troublesome and prevented him resting at night. In May last he began to suffer from "cramps" in the legs, and had to pass urine very frequently. In July the bladder became paralysed.

The patient was a tall, well-nourished man, but with rather a pale, pasty complexion. There was slight ptosis of the right eyelid. The right iris was green, the left brown, and the left pupil slightly larger than the right. The general health was good, and no abnormality was detected in the heart, Jungs, or organic viscera. The urine was neutral, of sp. gr. 1024, and free from albumen and sugar. The attitude of the patient was peculiar (see the figure). He was 